\title{
A Teoria do Flow na contribuição do engajamento estudantil para apoiar a escolha de jogos no ensino de programação
}

\author{
Tatyane S. C. da Silva ${ }^{1}$, Jeane C. B. de Melo ${ }^{2}$, Patricia C. de A. R. Tedesco ${ }^{1}$ \\ ${ }^{1}$ Universidade Federal de Pernambuco (UFPE) \\ Av. Prof. Moraes Rego, 1235 - Cidade Universitária - CEP: 50670-901 - Recife - PE \\ Brasil \\ ${ }^{2}$ Universidade Federal Rural de Pernambuco (UFRPE) \\ Rua D. Manoel de Medeiros, s/n - Dois Irmãos - CEP: 52171-900 - Recife - PE - Brasil \\ tscs@cin.ufpe.br, jeane.ufrpe@gmail.com, pcartecin.ufpe.br
}

\begin{abstract}
Disciplines related to the teaching of programming are fundamental for the formation of Computer Science Students. Some important skills are acquired from these disciplines, namely: to formulate solutions algorithmically and develop logical-mathematical reasoning. Difficulties commonly faced when acquiring such skills lead to the loss of light, motivation and even to course abandonment. In this light, this work proposes a set of guidelines to help the teacher to properly choose games for teaching programming, based on engagement techniques, player profiles and Flow state features, in order to help students increase their motivation.
\end{abstract}

Resumo. Disciplinas relacionadas ao ensino de programação são fundamentais para formação dos estudantes de Ciência da Computação. Algumas habilidades importantes são adquiridas de tais disciplinas, a saber: formular soluções algoritmicamente e desenvolver o raciocínio lógicomatemático. Dificuldades enfrentadas na aquisição de tais habilidades levam à desmotivação e até mesmo ao abandono do curso. Assim, este trabalho tem o intuito de propor diretrizes para auxiliar o professor na escolha adequada de jogos para o ensino de programação baseada em técnicas de engajamento, perfis de jogadores e características do estado de Flow, com o intuito de auxiliar o aumento da motivação dos alunos.

\section{Introdução}

A disciplina de programação é identificada como base na formação acadêmica e profissional de estudantes de Ciência da Computação. Contudo, o raciocínio lógico inerente ao aprendizado dessa matéria, e a forma de abordar os problemas, são de difícil assimilação para a maioria dos discentes (Duduchi e Souto 2009).

Uma forma comum de iniciar o ensino de programação é enfatizar os detalhes sintáticos de uma linguagem, antes de desenvolver aspectos lógicos e semânticos. No entanto, para estudantes recém-ingressos nos cursos de Computação, se adequar à nova forma de resolver problemas através do computador é uma necessidade preeminente ao conhecimento da sintaxe de uma linguagem de programação (Gomes et al. 2008).

Outro aspecto a ser considerado é o desenvolvimento de uma metodologia que contribua para o aumento do engajamento do estudante, o qual pode ser observado através da participação do discente nas atividades (Fredricks et al. 2004). Para isto, faz- 
se necessário criar experiências mais significativas durante o processo de aprendizagem de programação, por exemplo, através da introdução de games, como um fator motivacional, no ensino desta disciplina (Silva et al. 2014).

Nesse contexto, uma vantagem expressiva na utilização de jogos no ensino é propiciar ao estudante a visualização do efeito de suas ações, promovendo a aprendizagem de maneira dinâmica, impactando positivamente na experiência educacional. $\mathrm{O}$ uso de jogos pode potencializar o engajamento do aluno, incentivar $\mathrm{o}$ total envolvimento com a atividade e promover um estado de imersão denominado de Flow. A Teoria do Flow foi criada por Csikszentmihalyi em 1990. Flow é um constructo e faz parte dos estudos das experiências do bem estar subjetivo, pesquisados pelo campo da Psicologia Positiva (Csikszentmihalyi 1990).

Diante deste cenário, o presente estudo tem a finalidade de propor diretrizes que auxiliem o professor a escolher adequadamente um jogo para o ensino de programação, considerando a maneira que os estudantes interagem com os jogos através dos seus estilos de jogadores, buscando levar o discente a alcançar o estado de Flow e, assim, promover uma aprendizagem mais eficaz. Este trabalho está organizado do seguinte modo: os trabalhos relacionados ao estudo descrito no presente artigo compõem a Seção 2; a Seção 3 apresenta a Teoria do Flow; a Seção 4 descreve o engajamento estudantil e seus indicadores; em seguida, na Seção 5 são abordados os perfis dos jogadores e técnicas de engajamento; na Seção 6 os critérios para escolha de jogos para ensino de programação são discorridos; na Seção 7 são apresentadas as considerações finais bem como trabalhos futuros.

\section{Trabalhos relacionados}

A literatura apresenta distintos estudos que abordam sobre o tema da utilização de jogos no ensino de programação no ensino superior. O estudo realizado por Eagle e Barnes (2009) resultou em melhorias nas notas dos discentes pela utilização de um jogo para praticar especificamente o conceito de loops na disciplina de introdução a programação. Silva et al. (2014) realizou uma Revisão Sistemática da Literatura sobre essa temática com o intuito de analisar a eficácia da utilização de jogos digitais para auxiliar o processo de ensino e aprendizagem de programação. $\mathrm{O}$ estudo foi realizado baseado em artigos publicados nos últimos cinco anos, em relevantes eventos e periódico na área no cenário internacional. $\mathrm{O}$ autor concluiu em seu estudo que os jogos digitais para o ensino estão voltados para melhorar o rendimento, interesse dos alunos em disciplinas de programação e esse método ajuda o desempenho dos estudantes, diminui as desistências e aumenta a motivação.

No que se refere ao engajamento estudantil através de jogos, Adamo-Villani et al. (2013) criaram um jogo 3D para auxiliar o ensino de programação. Os autores analisaram os resultados a partir de um estudo onde foram testadas à usabilidade, engajamento e eficácia do game com alunos de graduação. $\mathrm{O}$ jogo se passa em um labirinto tridimensional e para o personagem sair do labirinto precisa resolver problemas relacionados à matemática utilizando programação. A resposta correta permite que o jogador se aproxime da saída do labirinto, a solução incorreta move o jogador para a extremidade mais distante do labirinto. Como resultado da pesquisa, com 14 estudantes de graduação, os autores concluíram que o jogo foi relevante no aprendizado dos discentes em programação. 
Sobre a relação da teoria do Flow e engajamento estudantil Whitson e Consoli (2009) concluem no seu estudo que a teoria do Flow mostra um novo significado para o engajamento estudantil, como uma construção complexa que inclui cognição, motivação e emoção, não apenas uma observação do comportamento dos estudantes ao realizarem tarefas. Atingir o estado de Flow pode aumentar o envolvimento dos alunos no processo de aprendizagem, por meio de atividades que desafiem os estudantes, sendo essas equilibradas com as habilidades aprendidas. Outro aspecto destacado por Whitson e Consoli (2009) é a necessidade de fornecer um feedback significativo para os discentes, para que possam permanecer engajados com uma atividade de aprendizagem.

\section{Teoria do Flow}

Com o intuito de identificar o que leva o indivíduo a alcançar um estado de felicidade, Csikszentmihalyi (1990) desenvolveu uma pesquisa para compreender o que faz uma pessoa se sentir feliz na vida cotidiana. Com os primeiros resultados Csikszentmihalyi (1990) desenvolveu um padrão que denominou de "experiência ótima", sendo definido como "uma atividade realizada sem expectativa de algum benefício futuro, mas por que realizá-la é a própria recompensa" (Csikszentmihalyi, 1990, p. 67). O autor afirma que Flow é a maneira que os indivíduos descrevem seu estado de espírito quando a consciência está harmoniosamente ordenada e continuam realizando a atividade por vontade própria.

Nessa perspectiva, Csikszentmihalyi (1990) descreve algumas características que estão presentes quando a pessoa está em estado de Flow:

i. Foco e concentração: envolvimento total com a atividade.

ii. $\quad \hat{E} x t a s e:$ um sentimento de estar longe da realidade diária.

iii. Clareza/Feedback: este é um atributo que coopera para que o engajamento na atividade ocorra de maneira intensa, dado que o retorno rápido, de acordo com o que está sendo realizado, se torna um requisito para prosseguir com a atividade de forma prazerosa e satisfatória.

iv. Habilidades: as atividades são constituídas de desafios a serem realizados, todavia é necessário que o indivíduo apresente aptidão apropriada para cumpri-la.

v. Perda da sensação do tempo: o foco na atividade promove a sensação de estar além da dimensão temporal.

O estado de Flow possui algumas características que, em conjunto, cooperam para apontar o momento da "experiência ótima". Contudo, o desafio e a habilidade são os principais elementos que, quando combinados de forma equilibrada, podem contribuir para que o indivíduo alcance o seu estado de Flow. Para exemplificar, Csikszentmihalyi desenvolveu um diagrama, apresentado na Figura 1. 


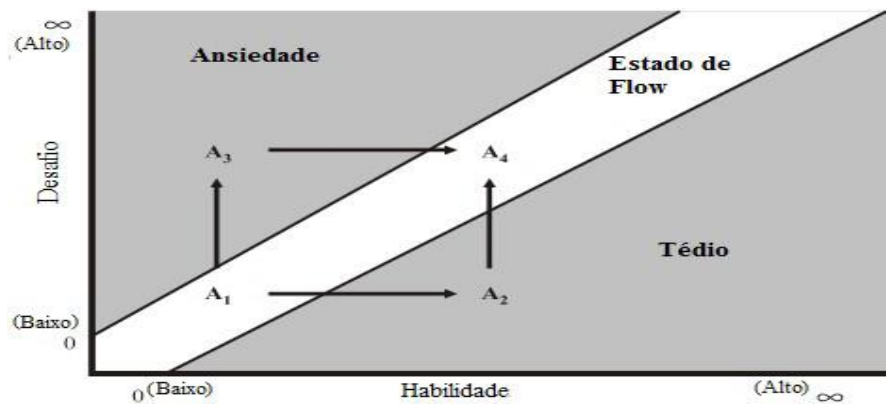

Figura 1 - Diagrama de Csikszentmihalyi (1990)

Os desafios e habilidades são as dimensões mais importantes apresentadas nos eixos do diagrama. Sempre que o jogador inicia uma atividade, o desafio ocorre baseado em sua habilidade (A1), nesse momento ele, provavelmente, está em estado de Flow. Contudo, isso logo se modifica em tédio (A2), dado que suas habilidades aumentaram e não condizem ao desafio inicial. Porém, quando um novo desafio é apresentado o sentimento passa a ser de ansiedade (A3), uma vez que o objetivo é vencer seu novo desafio e alcançar novamente o estado de Flow (A4).

\section{Engajamento estudantil}

Inúmeros estudos são encontrados na literatura sobre o engajamento de alunos e geralmente incluem, por exemplo, um componente comportamental e psicológico para defini-lo (Fredricks et al. 2004; Gibbs e Poskitt, 2010). Embora não haja um consenso sobre a definição de engajamento dos estudantes (Taylor e Parsons 2011), o envolvimento nas atividades é considerado um indicador de engajamento (Fredricks et al. 2004).

\subsection{Indicadores de engajamento}

Sobre o engajamento discente, a literatura mostra indicadores ou variáveis, no intuito de analisar se houve mudança no comportamento do aluno durante as atividades realizadas. Os indicadores encontrados na literatura são: Autonomia, Execução, Social, Entrega, Participação e Diversão. A Tabela 1 mostra os indicadores de engajamento, segundo Seixas (2014):

Tabela 1 - Indicadores de engajamento encontrados na Literatura

\begin{tabular}{|c|l|l|}
\hline Indicadores & \multicolumn{1}{|c|}{ Descrição } & \multicolumn{1}{|c|}{ Fonte } \\
\hline Autonomia & $\begin{array}{l}\text { O estudante toma suas decisões sem a intervenção contínua do } \\
\text { professor. }\end{array}$ & $\begin{array}{l}\text { Zepke } \text { et al. }(2010), \\
\text { Taylor e Parsons } \\
(2011) .\end{array}$ \\
\hline Execução & $\begin{array}{l}\text { O aluno realiza as atividades propostas pelo professor em sala } \\
\text { de aula. }\end{array}$ & Akey (2006). \\
\hline Social & $\begin{array}{l}\text { O discente apresenta um bom relacionamento com os colegas e e } \\
\text { o professor. }\end{array}$ & $\begin{array}{l}\text { Taylor e Parsons } \\
(2011) .\end{array}$ \\
\hline Entrega & O estudante realiza as atividades no prazo correto. & Akey (2006). \\
\hline Participação & O discente contribui nas discussões em sala. & Zepke et al. $(2010)$. \\
\hline Diversão & $\begin{array}{l}\text { O aluno realiza as atividades não apenas pela obrigação, mas } \\
\text { por considerar essas divertidas. }\end{array}$ & Prensky (2002). \\
\hline
\end{tabular}


Com o intuito de apoiar o engajamento discente, a próxima seção apresenta os perfis dos jogadores, suas características, como também as técnicas de engajamento e sua relação com os tipos de jogadores.

\section{Perfis dos jogadores e técnicas de engajamento}

O engajamento do indivíduo dentro de um ambiente pode se tornar eficaz através do gerenciamento da sua motivação e emoção. Esses sentimentos podem ser influenciados pela motivação intrínseca e/ou extrínseca (Zichermann e Cunningham 2011).

A motivação intrínseca é caracterizada pela vontade própria do indivíduo de realizar atividades, aceitar novos desafios, alcançar e aperfeiçoar as próprias capacidades. A motivação extrínseca, por sua vez, é baseada no desejo do indivíduo em alcançar uma recompensa externa, tais como, bens materiais e reconhecimento social (Ryan e Deci 2000).

Zichermann e Cunningham (2011), afirmam que para se projetar uma experiência ou guiar um comportamento de forma desejada é necessário compreender o comportamento do indivíduo dentro do contexto de jogo. Uma forma de identificar o usuário baseando-se em seu comportamento é recomendada por Bartle (1996), que propõe classificar os perfis dos jogadores nas categorias a seguir: predadores, conquistadores ou realizadores, comunicadores ou socializadores e exploradores. A Figura 2 ilustra os perfis dos jogadores.

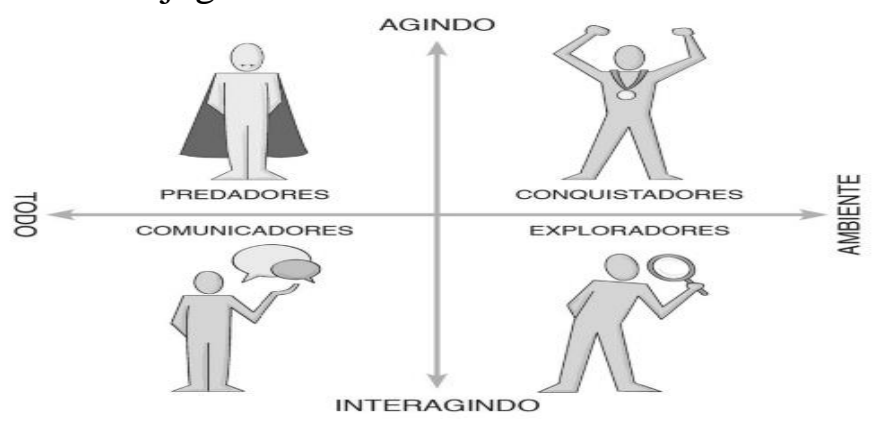

Figura 2 - Tipos de jogadores segundo Bartle (Alves 2014)

Os jogadores que têm o perfil predador interagem com outros jogadores de maneira intensa e competitiva (Bartle, 1996). O gráfico (Figura 2) mostra que os jogadores com perfil predador ocupam a posição de interesse em agir sobre outros jogadores.

Os jogadores classificados como conquistadores (Alves 2014), também chamados de realizadores (Sena e Coelho 2012), ocupam uma posição no gráfico (Figura 2) que confirma a relação que os mesmos têm com o mundo virtual. O que caracteriza os jogadores realizadores é a busca pela liderança no contexto do jogo, pois valorizam o status e a vitória.

Os exploradores, por sua vez, investigam o ambiente do jogo e tentam descobrir o máximo seus desafios. De acordo com o gráfico de Bartle, sua colocação está baseada no seu interesse de interagir com o ambiente do jogo (Figura 2).

Por fim, os jogadores comunicadores têm o interesse de interagir com outros jogadores, orgulham-se de suas amizades, seus contatos e sua influência. As pesquisas indicam que este é o perfil de jogador que aparece com mais frequência (Alves 2014). 
Embora o conhecimento dos perfis dos jogadores auxilie a inclusão de elementos que podem explorar a motivação intrínseca no desenvolvimento dos games, a garantia do sucesso do jogo é influenciada também por outros fatores. As técnicas de engajamento são utilizadas com intuito de motivar os jogadores e garantir que os mesmos fiquem maior tempo jogando (Sena e Coelho 2012). A seguir são apresentadas algumas técnicas de engajamento:

i. Desafios e Missões: embora os jogos tenham objetivos a serem alcançados, há alguns jogadores que começam a jogar sem ter ciência das metas. Assim, usar desafios e missões é uma opção para inserir profundidade e significado para o jogador (Zichermann e Cunningham 2011).

ii. Achievements ou Badges: recompensas dadas aos jogadores após alcançar uma conquista ou cumprir uma tarefa.

iii. Progress Bar: sua finalidade é mostrar ao jogador sua evolução ao longo do jogo.

iv. Gifting: tem como objetivo aumentar a interação social através de estímulos dados ao jogador para presentear seus amigos, que podem ser jogadores do mesmo game ou não.

v. Rankings e LeaderBoard: mantém a motivação dos jogadores através da competição entre eles.

Nessa perspectiva, segundo Sena e Coelho (2012), pode-se fazer a relação entre as técnicas de engajamento, tendo em vista o perfil do jogador, como pode ser observado na Tabela 2.

Tabela 2 - Relação entre técnicas de engajamento e perfil dos jogadores

\begin{tabular}{|c|l|}
\hline Técnicas de engajamento & \multicolumn{1}{|c|}{ Perfil do Jogador } \\
\hline Achievements ou Badges. & $\begin{array}{l}\text { Realizadores, Socializadores } \\
\text { Exploradores. }\end{array}$ \\
\hline Desafios e Missões. & Realizadores e Exploradores. \\
\hline Rankings e LeaderBoards. & Predadores e Socializadores. \\
\hline Progress Bar. & \multicolumn{1}{|c|}{ Todos. } \\
\hline
\end{tabular}

\section{Critérios para escolha de jogos para ensino de programação}

A presente seção propõe diretrizes que podem auxiliar o docente na seleção de jogos que contribuam com o ensino de programação, objetivando engajar o estudante nesse processo de aprendizagem. A fundamentação teórica segue a proposta da Teoria do Flow que é um estado mental de funcionamento no qual, ao realizar alguma atividade o indivíduo apresenta uma sensação de foco completo, com um alto nível de diversão e satisfação. Para esse fim, são apresentados alguns exemplos de jogos que permitem identificar relações entre as características de Flow, técnicas de engajamento e perfis de jogadores, podendo conduzir a utilização de jogos no ensino de programação.

A fim de ilustrar as propriedades a serem observadas na escolha de jogos para ensino de programação, foram selecionados os seguintes jogos: CodeCombat, CodeSchool no módulo Rails for zombie e Belesminha. O critério de escolha baseou-se nas características que os games apresentaram, tais como: diversão, técnicas de engajamento e promover o estado de Flow. 
A primeira relação observada dá-se entre as características do estado de Flow: Foco/ Concentração, perda da sensação de tempo, êxtase, e as técnicas de engajamento: Desafios e Missões, Achievements ou Badges, Rankings e LeaderBoards. Todos os perfis de jogadores são considerados, sendo o jogo sugerido para observá-los o CodeCombat. O CodeCombat está disponível online e tem o objetivo de ensinar os conceitos de lógica, sintaxe formal e variáveis. As linguagens disponíveis são: python, javascript, clojure, lua e Io. O jogo é definido em um reino de fantasia no qual o jogador deve codificar para derrotar as forças das hordas dos ogros saqueadores. Os comandos executados pelos jogadores englobam: mover (esquerda, direito, para cima, para baixo), atacar e defender. O jogador tem um avatar que dispõe de itens que aumentam seu poder no game e podem ser adquiridos pelas Gemas, que são recursos pagos. O jogo contempla todos os perfis dos jogadores, e cada um pode interagir de forma diferente:

i. os predadores: encontram no jogo uma competição no módulo mutiplayer e ranking.

ii. os realizadores: o jogo oferece badges, recompensas após cada missão e desafio realizados com sucesso;

iii. os exploradores: a questão da descoberta de itens do inventário do CodeCombat, a cada nível alcançado motiva os jogadores desse perfil;

iv. os socializadores: também se motivam com esse jogo, pois existe a funcionalidade de conectar ao google+ e ver quais amigos estão jogando também.

Nessa perspectiva, o CodeCombat ajudará a promover o estado de Flow dos estudantes, devido ao seu ambiente imersivo e divertido apresentando elementos de motivação e iteração diferentes para cada perfil de jogador.

A segunda relação a ser destacada envolve as características do estado de Flow: Clareza/Feedback, as técnicas de engajamento ProgressBar, Achievements ou Badges. Os perfis de jogadores envolvidos são os realizadores e exploradores, observados no módulo Rails for zombies do jogo CodeSchool. O CodeSchool é voltado para o ensino de lógica de programação e sintaxe, e, encontra-se disponível online. Os níveis do jogo são alcançados na medida em que os jogadores realizam a tarefa designada. Os comandos executados pelos jogadores englobam a escrita de linhas de códigos para realizar uma determinada tarefa a ser cumprida. O jogo contempla o perfil do jogador realizador e explorador, pois ao final do game o jogador recebe um badge. No decorrer do game o jogador pode ainda verificar sua evolução através do progress bar. O jogo tem o intuito de ser divertido, pois aborda o tema de zombies fazendo com que os jogadores pratiquem a programação. Esse fatores, somados à clareza e ao feedback imediato relativo às interações realizadas pelos jogadores, indicam que o CodeSchool pode ajudar a promover o estado de Flow.

No jogo Belesminha, a característica Habilidades relaciona-se com as técnicas de engajamento Desafios e Missões e favorece os jogadores com perfis realizadores e exploradores. Nesse jogo, o estudante controla uma lesma, a Belesminha, para recolher todas as folhas de laranjeira espalhadas pelo cenário. Os comandos são: ir para frente, virar à direita e virar à esquerda. $\mathrm{O}$ intuito do jogo é ensinar recursividade. $\mathrm{O}$ Belesminha aborda funções e suas respectivas chamadas recursivas. Os jogadores são motivados pelos desafios e missões a serem cumpridos. A dificuldade das questões aumenta de acordo com a habilidade adquirida a cada nível alcançado. As habilidades 
obtidas trazem confiança ao jogador e causa o envolvimento cada vez maior com o jogo, propiciando o estado de Flow.

As relações entre características, engajamento e perfis destacadas nesta seção são resumidas na Tabela 3. Os jogos aqui citados exemplificam as relações de modo concreto, visando auxiliar sua identificação, nestes e em outros jogos, e, assim, propor critérios de escolha dos mesmos, conforme as peculiaridades dos atores envolvidos.

Tabela 3 - Resumo da relação entre: Característica do estado de Flow, técnicas de engajamento, o perfil do jogador e jogos sugeridos

\begin{tabular}{|c|c|c|c|}
\hline $\begin{array}{c}\text { Característica do estado de } \\
\text { Flow }\end{array}$ & $\begin{array}{c}\text { Técnicas de } \\
\text { engajamento }\end{array}$ & $\begin{array}{c}\text { Perfis de } \\
\text { jogadores }\end{array}$ & Jogos sugeridos \\
\hline $\begin{array}{c}\text { Foco / Concentração e Perda } \\
\text { da sensação de tempo e êxtase }\end{array}$ & $\begin{array}{c}\text { Desafios Missões } \\
\text { Achievements ou Badges } \\
\text { Rankings e } \\
\text { LeaderBoards }\end{array}$ & Todos & CodeCombat \\
\hline Clareza/Feedback & $\begin{array}{c}\text { Progress Bar } \\
\text { Achievements ou Badges }\end{array}$ & $\begin{array}{c}\text { Realizadores e } \\
\text { Exploradores }\end{array}$ & $\begin{array}{c}\text { CodeSchool } \text { - módulo: } \\
\text { Rails for zombies }\end{array}$ \\
\hline Habilidades & Desafios e Missões & $\begin{array}{c}\text { Realizadores e } \\
\text { Exploradores }\end{array}$ & Belesminha \\
\hline
\end{tabular}

\section{Considerações finais e trabalhos futuros}

A programação é a base para formação do estudante e profissional de Computação, sendo utilizada na resolução de problemas reais. No entanto, as dificuldades encontradas para desenvolver o raciocínio lógico matemático, analisar e formular soluções para resolver os problemas algoritmicamente podem interferir no aperfeiçoamento dessa habilidade. Tais dificuldades são a grande causa, segundo Martins e Correia (2003), de reprovação, desmotivação e desistência dos estudantes nos cursos de Computação.

Diante desse panorama, promover o engajamento estudantil durante o período de ensino e aprendizagem dessa disciplina é um desafio que pode ser superado com a utilização de jogos e técnicas de engajamento. Se escolhidos de forma adequada, o estado de Flow do estudante será mantido ou promovido através dos jogos, aumentando a chance de garantir o engajamento dos discentes.

Deste modo, este artigo propôs diretrizes para auxiliar o docente na escolha de jogos para o ensino de programação e apresentou alguns exemplos de games, com o intuito de manter e/ou promover o engajamento estudantil, através da relação do perfil dos jogadores, técnicas de engajamento e características do estado de Flow. Tal proposta pode ser considerada uma generalização, uma vez que Bartle (1996) afirma que os jogadores podem apresentar, mesmo em menor grau, características de diversos perfis concomitantemente.

Uma proposta de trabalho futuro é a utilização dos jogos selecionados ou outros que apresentam as características semelhantes. A população do grupo experimental consistirá de estudantes do primeiro período matriculados na disciplina de introdução à programação do curso de Ciência da Computação. O grupo de controle será formado 
por alunos do primeiro período matriculados na disciplina de introdução à programação do curso de Ciência da Computação. Esse grupo será escolhido, pois os estudantes terão, em sua maioria, o conhecimento de programação equivalente aos discentes do grupo experimental. Antes de utilizar os games em uma turma, serão identificados os perfis dos jogadores usando o teste de Bartle, que apresenta uma série de perguntas e como resultado gera o percentual de cada perfil de jogadores que o indivíduo possui e qual deles é mais evidente (Wei 2009). A realização de um pré-teste com os discentes será efetuado, com perguntas para identificar se os alunos estão engajados e em estado de Flow antes das intervenções com os jogos. Para mensurar as respostas dos questionários a escala de Likert (1932) será usada. Para a confiabilidade do questionário será utilizado o coeficiente de Alpha de Cronbach que é uma forma de estimar a confiabilidade de um questionário aplicado em uma pesquisa, o valor aceitável do alpha deve ser superior a 0,7 (Kline 2000). Após a intervenção será aplicado um questionário, pós-teste, com os discentes para analisar se houve engajamento dos estudantes através dos indicadores e se estão em estado de Flow. A abordagem metodológica que será utilizada é o experimento, o método foi escolhido, pois possibilita a análise quantitativa dos dados, consolida a relação de causa e efeito em um ambiente controlado e os resultados podem ser assumidos como gerais e aplicáveis a uma comunidade ampla.

\section{Referências}

Adamo-Villani, N.; Haley-Hermiz, T.; Cutler, R. (2013). "Using a Serious Game Approach to Teach 'Operator Precedence' to Introductory Programming Students". In: International Conference Information Visualisation - IV, p.523-526.

Akey, T. M. (2006). "School context, student attitudes and behavior, and academic achievement: An exploratory analysis". New York: MDRC. Disponíveem: http://www.mdrc.org/publications/419/full.pdf.

Alves, F. (2014). Gamification. Como Criar Experiências de Aprendizagem Engajadoras. Um Guia Completo. Do Conceito à Prática. São Paulo, Editora DVS, $1^{\text {a }}$ edição.

Bartle, R. (1996). "Heart, Clubs, Diamond, Spades: players who suit muds". The Journal of Virtual Environments, 1(1).Disponívelem: http://www.mud.co.uk/richard/hcds.hm.

Belesminha. http://homepages.dcc.ufmg.br/ flavioro/belesminha/

CodeCombat. http://codecombat.com/

Code School. https://www.codeschool.com/

Csikszentmihalyi, M. (1990). Flow: the psychology of optimal experience. New York, NY, USA: Harper \&Row.

Duduchi, M.; Souto, A. V. (2009). "Um processo de avaliação baseado em ferramenta computadorizada para o apoio ao ensino de programação de computadores". Anais do XVII WEI.

Eagle, M.; Barnes, T. (2009). "Experimental Evaluation of an Educational Game for Improved Learning in Introductory Computing". In: Technical Symposium on Computer Science Educatio N, 40., Chattanooga, USA. Proceeding. USA: ACM, p. 321-325. 
Fredricks, J. A.; Blumenfeld P. C.; Paris A. H. (2004). "School Engagement: Potential of the Concept, State of the Evidence". Review of Educational Research. Spring, Vol. 74, No. 1, pp. 59-109.

Gibbs R.; Poskitt J. (2010) Student Engagement in the Middle Years of Schooling (Years 7-10): A Literature Review. Report to the Ministry of Education.

Gomes, A.; Henriques, J.; Mendes, A. J. (2008). Uma proposta para ajudar alunos com dificuldades na aprendizagem inicial de programação de computadores. Educação, Formação\&Tecnologias, vol. 1 (1), Maio.

Kline, P. The handbook of psychological testing. Routledge: London, 2000.

Likert, R. A technique for the measurement of attitudes. Archives of Psychology. v. 22, n. 140, p. 44-53, 1932.

Martins, S. W. e Correia, L. H. A. (2003). "O Logo como ferramenta auxiliar no desenvolvimento do raciocínio lógico - um estudo de caso". Internacional Conference on Engineering and Computer Education - ICECE Disponívelem: http://www.dcc.ufla.br/ lcorreia/bibtex/icece2003.pdf.

Prensky, M. (2002). The motivation of gameplay: the real twenty-first century learning revolution.on the horizon, vol. 10. iss: 1 , pp.5-11.

Ryan,R.M., Deci,E.L.(2000). Intrinsic and Extrinsic Motivations: Classic Definitions and New Directions. Contemporary Educational Psychology 25, 54-67.

Seixas,L.R. (2014). "A Efetividade de Mecânicas de Gamificação sobre o Engajamento de Alunos do Ensino Fundamental". Dissertação de mestrado. Universidade Federal de Pernambuco - Programa de Pós-Graduação em Ciência da Computação. Pernambuco. Brasil.

Sena,A. e Coelho,D.K (2012). "Motivação dos Jogadores de Videogame - Uma breve visão sobre as Técnicas de Engajamento". XI SBGAMES.

Silva, T. R., Medeiros, T.J, Aranha, E.H.S. (2014). "Jogos Digitais para Ensino e Aprendizagem de Programação: uma Revisão Sistemática da Literatura". In: XXV Simpósio Brasileiro de Informática na Educação.

Taylor, L.; Parsons, J. (2011). Improving Student Engagement.Current Issues in Education.14(1).Vol. 14, No. 1. ISSN 1099-839X.

Wei,Q. Gamers and the Games They Play (2009). Monografia (Bachelor of Science): Faculty of Worcester Polytechnic Institute, Worcester, Estados Unidos.

Whitson, C., Consoli, J (2009). "Flow theory and student engagement." Journal of Cross-Disciplinary Perspectives in Education $2.1: 40$.

Zepke N.; Leach L.; Butler P. (2010). Student Engagement: What Is It and What Influences It?.Teaching\& Learning Research Initiative.

Zichermann, G. \& Cunningham, C., (2011). Gamification by Design: Implementing Game Mechanics in Web and Mobile Apps 1st ed., Sebastopol (CAN): O'Reilly Media, Inc. 